\title{
Damage to the endothelium in Sjögren's syndrome: lack of correlation with antinuclear antibody titre and presence of antibodies to SSA or SSB autoantigens
}

\author{
A D Blann, A C Wainwright, P Emery
}

\begin{abstract}
Serum levels of von Willebrand factor antigen (as an index of damage to the endothelium) and tissue antinuclear antibodies and antibodies to SSA (Ro)(which have been associated with vasculitis) and SSB (La) autoantigens were measured in patients with Sjögren's syndrome. Although high levels of all indices were recorded, there were no intercorrelations. This provides evidence that although tissue autoantibodies may be useful in confirming a diagnosis, they have no place in the pathological course of the disease and so may be an epiphenomenon.
\end{abstract}

Siögren's syndrome is an autoimmune exocrinopathy with highly variable systemic clinical features. Extraglandular features of Sjögren's syndrome include renal tubular acidosis, neuropathy, pancreatitis, and vasculitis. ${ }^{1}$ In the laboratory, autoantibodies to SSA (Ro), with or without autoantibodies to SSB ( $\mathrm{La}$ ), can be detected in up to $90 \%$ of patients. ${ }^{2}$ The occurrence of autoantibodies to SSA has been linked with vasculitis. ${ }^{34}$

Von Willebrand factor antigen is a specific product of endothelial cells, high levels indicating damage to the endothelium, as may occur in vasculitis. ${ }^{5}$ Increased levels of von Willebrand factor antigen have been reported in Siögren's syndrome. ${ }^{6}$ Against this background, we examined the part that autoantibodies and von Willebrand factor antigen play in Sjögren's syndrome.

Accepted for publication 29 May 1991

\section{Materials and methods}

Venous blood was obtained from patients with primary Siögren's syndrome attending the rheumatology clinics at the Queen Elizabeth Hospital, Birmingham and from age and sex matched asymptomatic hospital and laboratory staff. Criteria for a diagnosis of Siögren's syndrome included clinical features of xerophthalmia, xerostomia, and salivary gland enlargement. Serum samples were collected after centrifugation at $3000 \mathrm{rev} / \mathrm{min}$ for 10 minutes, and were stored at $-20^{\circ} \mathrm{C}$ until assayed.

Von Willebrand factor antigen was measured by an enzyme linked immunosorbent assay (ELISA) using commercial antisera (Dakopatts). ${ }^{7}$ Briefly, coating and conjugate antisera were diluted 1:500 in carbonate buffer and phosphate buffered saline $/ 0.05 \%$ Tween 20 respectively. Serum samples were diluted to $1: 20,1: 40$, and 1:80, and the colour was developed with OPD/hydrogen peroxide in a citrate buffer. The reaction was terminated with $0 \cdot 1 \mathrm{M}$ hydrochloric acid and the absorbance measured in a Titretek reader at $492 \mathrm{~nm}$. Samples from the National Institute of Biological Standards and Controls provided reference values.

The titre and pattern of antinuclear antibodies were detected by indirect immunofluorescence on cryostat sections of rat liver. Antibodies to SSA and SSB were detected by countercurrent immunoelectrophoresis using an extractable nuclear antigen poly II extract (Bio-Diagnostics) and their identity was established by Ouchterlony immunodiffusion with reference serum samples obtained from Bio-Diagnostics. ${ }^{8}$ Data were analysed by the Mann-Whitney U test, Student's $t$ test, the $\chi^{2}$ test, and the Spearman rank sum correlation coefficient.

\section{Results}

The table shows that von Willebrand factor antigen was increased in serum samples from patients with Sjögren's syndrome $\quad(n=23$, median $222 \mathrm{IU} / \mathrm{dl}$ ) relative to normal control serum samples $(\mathrm{n}=229$, median $89 \mathrm{IU} / \mathrm{dl}$, $\mathrm{p}<0.001$ ). Eleven of twenty three patients (48\%) had a high antinuclear antibody titre $(>1 / 400)$. The most common antinuclear antibody pattern was speckled. Antibodies to SSA were detected in 12 patients $(52 \%)$ and to SSB in six patients $(26 \%)$. Von Willebrand factor antigen did not correlate with the antinuclear antibody titre or pattern. The mean von Willebrand factor antigen in 12 patients positive for SSA was 206 (standard deviation (SD) 77); 
in 11 SSA negative patients it was 246 (127). Similarly, for subjects with antibodies to SSB, von Willebrand factor antigen levels were 196 (113), compared with 231 (105) in subjects without antibodies (all data not significant). There was a correlation between the antinuclear antibody titre and seropositivity to SSA $(\mathrm{p}<0.01)$, but not seropositivity to SSB.

\section{Discussion}

Vasculitis is a recognised feature of Siögren's syndrome and has been reported to be associated with antibodies to the SSA (Ro) autoantigen. ${ }^{34}$ This study confirms a previous report of high levels of von Willebrand factor antigen in patients with Sjögren's syndrome. ${ }^{6}$ Considerably fewer of our patients were positive for SSA or SSB than the $>80 \%$ of patients reported elsewhere. ${ }^{2}$ We found a strong correlation between a high antinuclear antibody titre and seropositivity for SSA, but were unable to correlate levels of von Willebrand factor antigen with levels of autoantibodies. As von Willebrand factor antigen is becoming recognised as a useful index of assessing vasculitis, 56910 our data do not support the view that autoantibodies to SSA or SSB, or both, are related directly to vasculitis in Sjögren's syndrome.

1 Moutsopoulos H M. NIH Conference. Sjögren's syndrome (sicca syndrome): current issues. Ann Intern Med 1980; 92: 212-26.

2 Harley J B, Alexander E L, Bias W B, et al. Anti-Ro (SS-A) and anti-La (SS-B) in patients with Sjögren's syndrome. Arthritis Rheum 1986; 29: 196-206.

3 Alexander E L, Arnett F C, Provost T T, Stevens M B. Sjögren's syndrome: association of anti-Ro (SS-a) antibodies with vasculitis, hematological abnormalities, and serologic hyperreactivity. Ann Intern Med 1983; 98: 155-9.

4 Molina R, Provost T T, Alexander E L. Two types of inflammatory vascular disease in Siögren's syndrome. Arthritis Rheum 1985; 28: 1251-8.

5 Woolf A D, Wakerley G, Wallington T B, Scott D G I, Dieppe P A. Factor VIII related antigen in the assessment of vasculitis. Ann Rheum Dis 1987; 46: 441-7.

6 Federici A B, Fox R I, Espinoza L R, Zimmerman T S Elevation of von Willebrand factor antigen is independent of erythrocyte sedimentation rate and persists after glucocorticoid treatment in giant cell arteritis. Arthritis Rheum 1984; 27: 1046-9.

7 Short P E, Williams C E, Picken A M, Hill F G H. Factor VIII related antigen: an improved immunoassay. Med Lab Sci 1982; 39: 351-5.

8 Scott D G I, Skinner R P, Bacon P A, Maddison P J. Precipitating antibodies to nuclear antigens in systemic vasculitis. Clin Exp Immunol 1984; 56: 601-6.

9 Belch J J F, Zoma A A, Richards I M, McLaughlin K, Forbes C D, Sturrock R D. Vascular damage and factorVIII-related antigen in the rheumatic diseases. Rheumato Int 1987; 7: 107-11.

10 James J P, Stevens T R J, Hall N D, et al. Factor VIII related antigen in connective tissue disease patients and relatives. Br F Rheumatol 1990; 29: 6-9. 